Revista Tecné, Episteme y Didaxis: TED. Año 2014, Número Extraordinario. ISSN Impreso: 0121-3814, ISSN web: 2323-0126

Memorias, Sexto Congreso Internacional sobre Formación de Profesores de Ciencias. 08 al 10 de octubre de 2014, Bogotá

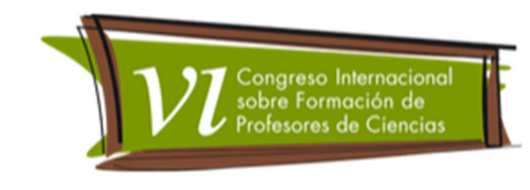

\title{
Las cuestiones sociocientíficas y el razonamiento moral y ético
}

Salazar Martínez Leidy Viviana', Pinzón Navarro Yadira Alexandra², Martínez Pérez Leonardo Fabio 3

Categoría 2. Trabajo de investigación (en proceso)

\section{Resumen}

En este artículo presentamos un análisis sobre el abordaje de cuestiones sociocientíficas en clases de ciencias en términos de sus aportes al razonamiento ético y moral de estudiantes de educación secundaria. El análisis es realizado a partir de la polémica concerniente a la legalización de la dosis personal como cuestión controvertida en la sociedad Colombiana, teniendo en cuenta las implicaciones ambientales, sociales, económicas y políticas que atañe la drogadicción. En el análisis también se sustenta la discusión de cuestiones sociocientíficas como una estrategia didáctica para generar en los educandos una posición crítica y responsable frente a la búsqueda de alternativas de solución a la problemática planteada y al fomento de la participación ciudadana.

Palabras clave: Enseñanza de las Ciencias, drogadicción, participación ciudadana y cuestiones sociocientíficas.

\section{Introducción}

Es importante reconocer que la sociedad actual, está permeada por antivalores (irresponsabilidad, deshonestidad, intolerancia, intransigencia), la indiferencia y la falta de compromiso en la construcción y desarrollo de la misma. Es decir, una sociedad del consumo, en donde predomina el bien propio y el interés por la adquisición de dinero y de bienes materiales, en ocasiones, desconsiderando la dignidad y el respecto de diferentes instancias de carácter político, económico, social, religioso y cultural, así como lo señala Botero (2004), que las dos últimas décadas de la historia colombiana se

\footnotetext{
${ }^{1}$ Magíster en Docencia de la Química, UPN. hadadeloslagos@yahoo.com

${ }^{2}$ Magíster en Docencia de la Química, UPN. yapin_15@hotmail.com

${ }^{3}$ Profesor del Departamento de Química UPN, Doctor en Educación en Ciencias. lemartinez@pedagogica.edu.co
} 
Revista Tecné, Episteme y Didaxis: TED. Año 2014, Número Extraordinario. ISSN Impreso: 0121-3814, ISSN web: 2323-0126 Memorias, Sexto Congreso Internacional sobre Formación de Profesores de Ciencias. 08 al 10 de octubre de 2014, Bogotá

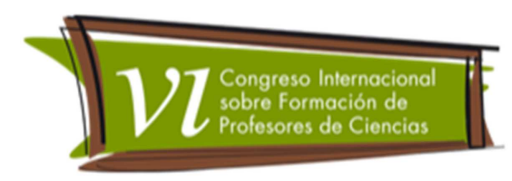

han caracterizado por una crisis de valores a partir de cuatro contradicciones básicas: a) Educación versus instrucción que forma individuos que pierden el sentido de servicio social o bien común. b) Bienestar y calidad de vida versus consumismo. c) Paz y justicia versus conflicto armado d) honestidad y transparencia versus corrupción y vida fácil. Por ende, tal crisis genera sujetos pasivos, poco arriesgados y sin autonomía, donde gobierna la ley del mínimo esfuerzo.

Por lo tanto la sociedad contemporánea requiere cambios en la transformación del consumismo a la del conocimiento, como lo indica Hargreaves (2003) construir una sociedad del conocimiento basada en habilidades como la creatividad, análisis, interpretación, inferencia, explicación, toma de decisiones entre otras, es decir donde los sujetos desarrollen habilidades que les permitan participar de su ciudadanía de manera crítica y responsable. Por ende educar, hoy en día, transciende del estudio de los contenidos de cada una de las asignaturas plasmadas en los currículos escolares, implica relaciones complejas y no lineales, en una dinámica basada en el poder entre profesor, estudiante, entorno y políticas educativas (Giroux, 1997). Así la educabilidad posibilita que el estudiante desarrolle y crezca intelectual, social y éticamente dentro de unas directrices formales constituidas por las instituciones educativas, que están direccionadas por concepciones epistemológicas, teorías pedagógicas, didácticas y curriculares, las cuales adquieren sentido en el interior de proyectos culturales, sociales, políticos y económicos.

Es así, como estos planteamientos son algunos elementos cruciales para contemplar la educabilidad de forma global y más específicamente en las ciencias, la cual tiene finalidades tales como propender por la preparación responsable de ciudadanos y científicos que sean capaces de optar por un posicionamiento propio sobre las implicaciones y/o polémicas que abarquen cuestiones de tipo ambiental, social, político, económico y ético de las actividades científicas y tecnológicas (tecnocientíficas). Como resalta Weissmann (1993) que la formación científica de los estudiantes debe contribuir a la formación de futuros ciudadanos responsables de sus actos, tanto individuales como colectivos, conscientes y conocedores de los riesgos, pero activos y solidarios para conquistar el bienestar de la sociedad, y finalmente críticos y exigentes frente a quienes toman las decisiones.

Para enseñar dichas implicaciones, se puede fundamentar en el enfoque Ciencia, Tecnología, Sociedad y Ambiente (CTSA) y específicamente en las llamadas cuestiones sociocientíficas (CSC), porque favorecen la reflexión sobre las ciencias poniéndolas en 
Revista Tecné, Episteme y Didaxis: TED. Año 2014, Número Extraordinario. ISSN Impreso: 0121-3814, ISSN web: 2323-0126 Memorias, Sexto Congreso Internacional sobre Formación de Profesores de Ciencias. 08 al 10 de octubre de 2014, Bogotá

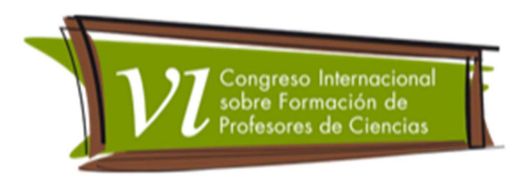

relación con la producción tecnológica y la dinámica social, así mismo valoriza la responsabilidad y la participación ciudadana en los debates relativos a la ciencia y la tecnología (Rubba y Wiesenmayer, 1988), promoviendo una dinámica educativa interdisciplinaria y crítica (Aikenhead, 1987).

Por consiguiente, este artículo tiene como finalidad mostrar las reflexiones que se dan a partir del uso de las CSC en clases de ciencias, como es el caso de la legalización de la dosis personal en Colombia, y como a partir dicha controversia los estudiantes de educación secundaria (grado sexto) realizan razonamientos éticos y morales alrededor de esta polémica. Estas reflexiones surgen a partir de investigaciones que realizan los autores en un trabajo denominado "Enculturación científica a través de la interdisciplinariedad de las cuestiones sociocientíficas (CSC)" (Pinzón y Salazar, 2012), en donde se analiza las interacciones discursivas entre los estudiantes y el profesor en clases de ciencias a través de la discusión de dos CSC: riego de hortalizas con agua del río Bogotá y la legalización de la dosis personal, a través de la implementación de dos unidades didácticas Contaminación del Agua y Sustancias Psicoactivas.

\section{Marco teórico}

Las cuestiones sociocientíficas y el razonamiento moral y ético

Dentro del enfoque CTSA, se pueden trabajar específicamente las llamadas cuestiones sociocientíficas (CSC), que implican conocimiento de frontera tales como: transgénesis, clonación, contaminación ambiental, fertilización en vitro, utilización de medicamentos y drogas, energías alternativas, armas nucleares, biotecnología etc. Se caracterizan por estar contextualizados en la vida real, ser relevantes para los estudiantes y ser abiertas (Jiménez-Aleixandre, 1998; Martínez, 2010). Son asuntos en los cuales se hace más explícita la naturaleza sociocultural del conocimiento científico y la mutua relación ciencia, tecnología y sociedad (CTS).

Kohlberg (1986, citado en Zeidler y Keefer, 2003) propone seis etapas morales en tres niveles, para comprender el razonamiento moral (tabla 1).

De acuerdo con las siguientes etapas los estudiantes a medida que van estudiando las cuestiones sociocientíficas inician la formación de un razonamiento moral, donde el trabajo en equipo es fundamental, al igual que los ambientes de negociación y disertación.

Temática 1. Enfoque CTS: Alfabetización científica y Cuestiones socio científicas 
Revista Tecné, Episteme y Didaxis: TED. Año 2014, Número Extraordinario. ISSN Impreso: 0121-3814, ISSN web: 2323-0126 Memorias, Sexto Congreso Internacional sobre Formación de Profesores de Ciencias. 08 al 10 de octubre de 2014, Bogotá

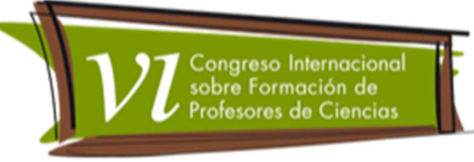

Tabla 1. Niveles y etapas morales 4

\begin{tabular}{|c|c|c|c|}
\hline Nivel y etapa & ¿Cuál es el adecuado? & $\begin{array}{l}\text { Las razones para hacer } \\
\text { lo correcto }\end{array}$ & $\begin{array}{c}\text { Perspectiva social de la } \\
\text { etapa }\end{array}$ \\
\hline \multicolumn{4}{|c|}{ Nivel I- preconvencional } \\
\hline $\begin{array}{l}\text { Ełapa } 1 \\
\text { Heterónoma } \\
\text { Moral }\end{array}$ & $\begin{array}{l}\text { Para evitar romper las } \\
\text { reglas respaldadas por } \\
\text { la obediencia castigo } \\
\text { por su propio bien, y } \\
\text { evitar daños físicos a } \\
\text { personas y bienes. }\end{array}$ & $\begin{array}{l}\text { Evitar el castigo y el } \\
\text { poder superior de las } \\
\text { autoridades. }\end{array}$ & $\begin{array}{l}\text { Punto de vista egocéntrico. } \\
\text { No considera los intereses } \\
\text { de otros o reconocen que } \\
\text { difierendel actor, no se } \\
\text { refiere dos puntos de vista. } \\
\text { Las acciones se consideran } \\
\text { físicamente más que en } \\
\text { términos de violencia } \\
\text { psicológicaintereses de los } \\
\text { demás. } \\
\text { Confusión de la perspectiva } \\
\text { de la autoridad con la } \\
\text { propia. }\end{array}$ \\
\hline $\begin{array}{l}\text { Etapa } 2 \\
\text { El } \\
\text { Individualismo, } \\
\text { instrumental } \\
\text { proponer e } \\
\text { intercambio }\end{array}$ & $\begin{array}{l}\text { Seguir las reglas sólo } \\
\text { cuando se trata de los } \\
\text { intereses inmediatos de } \\
\text { una persona, actuando } \\
\text { para satisfacer sus } \\
\text { propios intereses y } \\
\text { necesidades, y dejar } \\
\text { que los demás hagan lo } \\
\text { mismo. } \\
\text { Un intercambio } \\
\text { equitativo, un trato, un } \\
\text { acuerdo. }\end{array}$ & $\begin{array}{l}\text { Para servir las propias } \\
\text { necesidades o intereses } \\
\text { en un mundo donde } \\
\text { usted tiene que } \\
\text { reconocer que otras } \\
\text { personas también tienen } \\
\text { sus intereses. }\end{array}$ & $\begin{array}{l}\text { Perspectiva individualista } \\
\text { concreta. Consciente de } \\
\text { que todo el mundo tiene su } \\
\text { propio interés para } \\
\text { perseguir y estos conflictos, } \\
\text { por lo que el derecho es } \\
\text { relativo (en el sentido } \\
\text { individualista concreto). }\end{array}$ \\
\hline \multicolumn{4}{|c|}{ Nivel II - Convencional } \\
\hline $\begin{array}{l}\text { Etapa } 3 \\
\text { Mutua } \\
\text { interpersonal } \\
\text { expectativas, } \\
\text { relaciones } \\
\text { interpersonales y } \\
\text { conformidad }\end{array}$ & $\begin{array}{l}\text { A la altura de lo que se } \\
\text { espera de las personas } \\
\text { cercanas a usted o lo } \\
\text { que la gente en general } \\
\text { esperan de las personas } \\
\text { en su papel de hijo, } \\
\text { hermano, amigo, etc. } \\
\text { "Ser bueno" es } \\
\text { importante y significa } \\
\text { tener buenos motivos, } \\
\text { mostrando su } \\
\text { preocupación por los } \\
\text { demás. } \\
\text { significa También } \\
\text { relaciones mantener } \\
\text { como la confianza, la } \\
\text { lealtad, el respeto y la } \\
\text { gratitud. }\end{array}$ & $\begin{array}{l}\text { La necesidad de ser una } \\
\text { buena persona consigo } \\
\text { mismo y con los demás. } \\
\text { El deseo de mantener } \\
\text { las reglas y la autoridad, } \\
\text { que apoyan el buen } \\
\text { comportamiento } \\
\text { estereotipado. }\end{array}$ & $\begin{array}{l}\text { Perspectiva del individuo en } \\
\text { relación con otros } \\
\text { individuos. Consciente de } \\
\text { los sentimientos } \\
\text { compartidos, acuerdos y } \\
\text { expectativas, que tienen } \\
\text { primacía sobre los intereses } \\
\text { individuales. }\end{array}$ \\
\hline
\end{tabular}

${ }^{4}$ La información de la tabla fue traducida por los autores. Tomada de Zeidler y Keefer (2003, pp. 35-38).

Temática 1. Enfoque CTS: Alfabetización científica y Cuestiones socio científicas 
Revista Tecné, Episteme y Didaxis: TED. Año 2014, Número Extraordinario. ISSN Impreso: 0121-3814, ISSN web: 2323-0126 Memorias, Sexto Congreso Internacional sobre Formación de Profesores de Ciencias. 08 al 10 de octubre de 2014, Bogotá

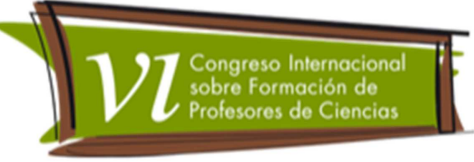

\begin{tabular}{|c|c|c|c|}
\hline $\begin{array}{l}\text { Etapa } 4 \\
\text { Social } \\
\text { sistema y } \\
\text { conciencia }\end{array}$ & $\begin{array}{l}\text { El cumplimiento de los } \\
\text { deberes reales a los que } \\
\text { estén de acuerdo. } \\
\text { Las leyes han de ser } \\
\text { confirmadas, excepto } \\
\text { en casos extremos en } \\
\text { los que entran en } \\
\text { conflicto con otras } \\
\text { obligaciones sociales } \\
\text { fijas. } \\
\text { También está } \\
\text { contribuyendo a la } \\
\text { sociedad, el grupo o } \\
\text { institución. }\end{array}$ & $\begin{array}{l}\text { Para evitar el colapso } \\
\text { del sistema "si todos lo } \\
\text { hicieran ", o el } \\
\text { imperativo } \\
\text { conciencia para cumplir } \\
\text { las obligaciones } \\
\text { definidas propias. }\end{array}$ & $\begin{array}{l}\text { Regla de Oro, ponerse en el } \\
\text { lugar de la otra persona. } \\
\text { Sigue sin tener en cuenta } \\
\text { perspectiva sistémica } \\
\text { generalizada. }\end{array}$ \\
\hline \multicolumn{4}{|c|}{ Nivel III - Post-convencional, o de principios } \\
\hline $\begin{array}{l}\text { Etapa } 5 \\
\text { sociales } \\
\text { Contrato o } \\
\text { Utilidad } \\
\text { e Individual }\end{array}$ & $\begin{array}{l}\text { Consciente de que la } \\
\text { gente tiene una } \\
\text { variedad de valores y } \\
\text { opiniones que la } \\
\text { mayoría de los valores y } \\
\text { las reglas son relativas a } \\
\text { su grupo. Estas reglas } \\
\text { relativas generalmente } \\
\text { deben ser defendidas. } \\
\text { Sin embargo, en aras } \\
\text { de la imparcialidad y } \\
\text { porque son el contrato } \\
\text { social. } \\
\text { Algunos valores como } \\
\text { la vida y la libertad, } \\
\text { deben respetarse en } \\
\text { cualquier sociedad y } \\
\text { con independencia de } \\
\text { la opinión mayoritaria. }\end{array}$ & $\begin{array}{l}\text { Un sentido de la } \\
\text { obligación de la ley por } \\
\text { causa de su contrato } \\
\text { social para hacer y } \\
\text { cumplir con los mínimos } \\
\text { para el bienestar de } \\
\text { todos y para la } \\
\text { protección de los } \\
\text { derechos de todas las } \\
\text { personas. El sentimiento } \\
\text { de compromiso } \\
\text { contractual, escogida } \\
\text { libremente, a la familia, } \\
\text { la amistad, obligaciones } \\
\text { confianza y trabajo. La } \\
\text { preocupación de que } \\
\text { las leyes y los deberes se } \\
\text { basan en el racional } \\
\text { cálculo de utilidad } \\
\text { general, "el mayor bien } \\
\text { para el mayor número". }\end{array}$ & $\begin{array}{l}\text { Distingue el punto de vista } \\
\text { de acuerdo o motivos } \\
\text { interpersonales. Toma el } \\
\text { punto de vista del sistema } \\
\text { que define roles y reglas. } \\
\text { Considera las relaciones } \\
\text { individuales en términos de } \\
\text { su lugar en el sistema. }\end{array}$ \\
\hline $\begin{array}{l}\text { Etapa } 6 \\
\text { universal } \\
\text { Principios éticos }\end{array}$ & 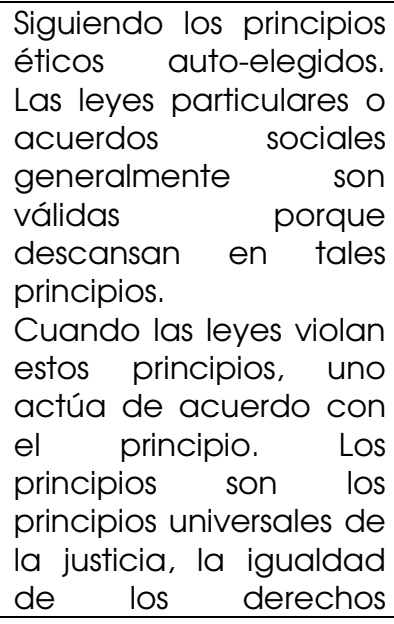 & $\begin{array}{l}\text { La creencia de que una } \\
\text { persona racional en la } \\
\text { validez de los principios } \\
\text { morales universales, y un } \\
\text { sentido de compromiso } \\
\text { personal con ellos }\end{array}$ & $\begin{array}{l}\text { Con anterioridad a la } \\
\text { sociedad perspectiva. } \\
\text { Perspectiva de un racional } \\
\text { individuo consciente de los } \\
\text { valores y los derechos } \\
\text { sociales antes de los } \\
\text { accesorios y contratos. } \\
\text { Integra las perspectivas de } \\
\text { mecanismos formales de } \\
\text { acuerdo, contrato, } \\
\text { imparcialidad objetiva, y } \\
\text { debido proceso. Considera } \\
\text { puntos morales y legales. } \\
\text { La perspectiva es la de } \\
\text { cualquier individuo racional } \\
\text { reconoce la naturaleza de }\end{array}$ \\
\hline
\end{tabular}


Revista Tecné, Episteme y Didaxis: TED. Año 2014, Número Extraordinario. ISSN Impreso: 0121-3814, ISSN web: 2323-0126 Memorias, Sexto Congreso Internacional sobre Formación de Profesores de Ciencias. 08 al 10 de octubre de 2014, Bogotá

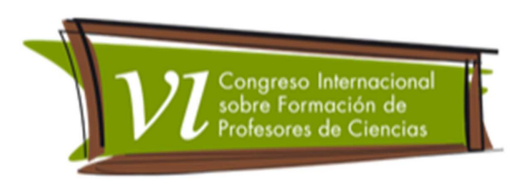

\begin{tabular}{|l|l|l|l|}
\hline & $\begin{array}{l}\text { humanos y el respeto } \\
\text { por la dignidad de los } \\
\text { seres humanos como } \\
\text { seres individuales. }\end{array}$ & $\begin{array}{l}\text { la moral o el hecho de que } \\
\text { las personas son fines en sí } \\
\text { mismos y deben ser tratados } \\
\text { como tales. }\end{array}$ \\
\hline
\end{tabular}

La legalización de la dosis personal "una cuestión sociocientífica"

Teniendo en cuenta que Colombia enfrenta un panorama de incertidumbre frente al tema del consumo, producción y expendio de drogas, no solo hacia el exterior sino en el interior del país, esta problemática puede ser usada en el aula de clase como herramienta de discusión debido a que presenta las cualidades representativas de las CSC, es decir que hace parte de la realidad Colombiana, genera controversia y está asociada a conceptos, productos y procedimientos científicos. Por esta razón la tan polémica legalización de la dosis personal puede actuar como dinamizadora en la construcción y formación del discurso sociomoral de los educandos. Entendido este como el reconocimiento de factores asociados a la cuestión controvertida, implicaciones sociales, posición crítica y responsable frente a la búsqueda de alternativas de solución o mitigación del problema.

Es posible un acercamiento a la autorreflexión, haciendo uso de los conocimientos científicos, sociales, afectivos y biológicos, que van desde la mutua integración de conceptos, metodología, procedimientos, datos y organización hasta un esfuerzo alrededor de la problemática común. Siendo pertinente reconocer que el consumo de sustancias psicoactivas ha incrementado en los adolescentes y jóvenes colombianos como lo muestra el estudio nacional de consumo de sustancias psicoactivas en población escolar (Gobierno Nacional, 2011), donde el cannabis es la sustancia ilícita que más se consume, seguida de psicoestimulantes y cocaína, que además de ser una preocupación social es una responsabilidad gubernamental y política puesto que la mayoría de los consumidores no acuden a servicios de tratamiento y las consecuencias de su consumo terminan con implicaciones negativas en la salud física y mental de la población adicta, debido a que el consumo de una sustancia psicoactiva implica el acondicionamiento de otras.

Es importante resaltar que para que los estudiantes asuman una postura en contra o a favor de la legalización de la dosis personal, tanto en consumo, producción y expendio; deben conocer diferentes razones asociadas, implicaciones y tipos de repercusiones psicológicas y sociales que generan las sustancias psicoactivas. 
Revista Tecné, Episteme y Didaxis: TED. Año 2014, Número Extraordinario. ISSN Impreso: 0121-3814, ISSN web: 2323-0126 Memorias, Sexto Congreso Internacional sobre Formación de Profesores de Ciencias. 08 al 10 de octubre de 2014, Bogotá

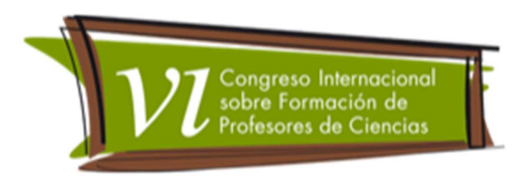

Resultados obtenidos en investigaciones permiten observar que hay una asociación entre el consumo de drogas y la aparición de ciertas enfermedades especialmente relevantes: las psiquiátricas, las neurológicas, las pulmonares y las cardíacas. Tal como lo dice la Organización Mundial de la Salud (OMS) en el 2004, el órgano más afectado por el consumo de drogas es el cerebro, pues se ha observado que ciertos procesos cognitivos y psicológicos como la emoción, la memoria y la motivación se muestran bastante comprometidos. Sin olvidar las repercusiones que puede llegar a tener este tipo de enfermedades sobre el individuo, pues pueden generar graves daños para la persona y para la misma sociedad.

El sólo hecho de no tratar este tema a tiempo significa pérdidas a nivel humano, social y económico, teniendo en cuenta el bajo promedio de edad de los consumidores y el limitado tiempo de evolución de los trastornos identificados, es probable que de mantenerse el consumo, se presenten patologías más severas; por ende se evidencia la necesidad de construir y/o modificar las políticas públicas en el área de la salud (Correa, 2009), de educar para la toma de conciencia frente a esta problemática fortaleciendo las intervenciones en prevención del consumo de drogas e implementación de acciones que den respuesta al problema en su actual dimensión, cuya responsabilidad trasciende la esfera del Gobierno e involucra a la familia, el barrio, la escuela, la universidad, los medios de comunicación y a la sociedad en general ( Gobierno Nacional, 201 1).

El debate sobre las bondades y perjuicios de la legalización ha cobrado especial interés en el país, propuestas provenientes de distintos sectores sociales, políticos y académicos coinciden en que para desincentivar el negocio del narcotráfico, es necesario legalizar las drogas y facultar al Estado para regular el mercado de las sustancias psicoactivas (SPA); otras por el contrario, ven en la legalización un problema adicional, debido a que su aplicación generaría efectos perversos de salud pública, descomposición social y finalmente recrudecimiento del conflicto interno.

Así, es pertinente recalcar que la legalización de las drogas implica una total modificación jurídica, y la regulación por parte de Estado en cuanto a la producción, comercialización y distribución del bien en cuestión (Vergara et al, 2003). La experiencia respecto a la despenalización, regulación y descriminalización de las SPA en países como Inglaterra, Suiza y Estados Unidos deja un sinsabor en los resultados pues hubo incremento de adictos, tráfico ilegal, mortalidad por sobredosis y delincuencia debido al deterioro de la seguridad ciudadana, por lo cual las medidas

Temática 1. Enfoque CTS: Alfabetización científica y Cuestiones socio científicas 
Revista Tecné, Episteme y Didaxis: TED. Año 2014, Número Extraordinario. ISSN Impreso: 0121-3814, ISSN web: 2323-0126 Memorias, Sexto Congreso Internacional sobre Formación de Profesores de Ciencias. 08 al 10 de octubre de 2014, Bogotá

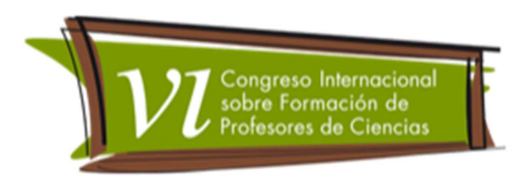

fueron abolidas, pero en otros países como Holanda la distribución controlada y los tratamientos de desintoxicación han permitido la reducción de usuarios toxicómanos infectados con el $\mathrm{VIH}$, la mortalidad por sobredosis y disminución de la delincuencia, por lo cual la medida continua vigente.

\section{Resultados y análisis}

El análisis conceptual y reflexivo la CSC legalización de la dosis personal en el aula, como lo muestran Pinzón y Salazar (2012) no solo permite el desarrollo de habilidades de pensamiento crítico sino que a la vez potencia la conciencia moral y ética del individuo, lo cual se evidencia desde el desarrollo inicial de la cuestión controvertida, partiendo del individualismo o nivel preconvencional en el razonamiento moral, donde el estudiante busca satisfacer y dar respuesta a sus propias necesidades como la memorización de apartados textuales sin apropiación interna para dar cuenta de una respuesta que se le solicita, reflejando relaciones de simplicidad entre términos y prevaleciendo la realidad del estudiante como se muestra en el episodio $10^{5}$ en el cual se desarrollan fragmentos de las actividades sobre clasificación de la sustancias psicoactivas y los efectos en el organismo.

1. A4-P: inicien con la exposición pasa E-1

2. A4-EM-1: yo tenía (que exponer sobre) la cocaína que es una droga estimulante y poderosamente adictiva. Las personas que la han probado describen la experiencia como una euforia que les da una sensación de supremacía. Sin embargo, una vez que la persona comienza a usar cocaína, no se puede predecir ni controlar hasta qué punto continuará usando la droga.

3. A4-P: ¿nos puedes explicar que es la euforia?

4. A4-EM-1: yo entendí que es cuando una persona esta muy (....) activa, como muy contenta y alocada

5. (/)A5- P: después de revisar los videos que se pedía en la guía ¿Cuál consideran que es la importancia de conocer los efectos que causan las drogas en el organismo?

6. A5-EM-1: es bueno conocer los efectos porque así tenemos razones suficientes para no consumir o dejar de consumir, pues las sustancias psicoactivas afectan

\footnotetext{
${ }^{5}$ Los episodios corresponden a fragmentos de las transcripciones realizadas en el desarrollo de la CSC, así el episodio 10 hace referencia a las exposiciones de los estudiantes sobre las sustancias psicoactivas.
} 
Revista Tecné, Episteme y Didaxis: TED. Año 2014, Número Extraordinario. ISSN Impreso: 0121-3814, ISSN web: 2323-0126 Memorias, Sexto Congreso Internacional sobre Formación de Profesores de Ciencias. 08 al 10 de octubre de 2014, Bogotá

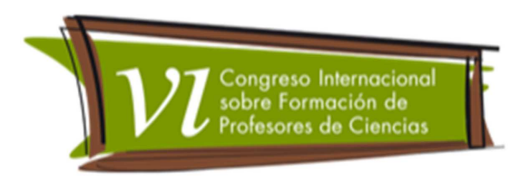

al sistema neurológico y altera los órganos y por eso se sienten sensaciones en nuestro cuerpo.

El desarrollo de las actividades para el abordaje de la cuestión controvertida involucra el uso de agentes sociales y discusiones formativas en pequeños grupos, lo cual permite poner a prueba las interpretaciones que se hacen frente a una misma situación. Donde los estudiantes se apropian de los significados cuando le son útiles para entender una situación o para resolver una problemática, en palabras de Strike y Posner (1990) cuando les sirven para estructurar los problemas que se les plantean, no solo siendo útil para resolver los problemas actuales, sino que sugiera formas de abordar el mundo, abriendo nuevas líneas de indagación y convirtiéndose en una herramienta útil del pensamiento.

Se observa que los estudiantes perciben, construyen y asimilan los significados de los conceptos científicos con el fin de comprender y explicar una situación de carácter social aproximándose a la etapa interpersonal del nivel de razonamiento moral convencional en donde prevalecen las normas, leyes y acuerdos sociales, denotando como ejes integradores, el dialogo con el profesor, el trabajo cooperativo, la discusión y los debates, lo cual permite facilitar la comprensión y entendimiento sobre las situaciones sociales y generar posición frente a ellas, como se presenta en el episodio 18 que sintetiza algunos aportes de los educandos sobre aspectos positivos y negativos de la legalización de la dosis personal en Colombia.

1. A3-P:realicen un listado de 5 aspectos positivos y 5 negativos que se verían en la sociedad Colombiana actual si se llegará a legalizar la droga, teniendo en cuenta las experiencias de los países que aparecen en el cuadro.

2. A3-EM-1: en mi grupo decidimos que no hay nada positivo porque las drogas o mejor dicho las sustancias psicoactivas no tienen nada bueno, y como aspectos negativos tenemos que aumentaría el número de adictos, (...) sería un problema más en la comunidad y habría más inseguridad en los barrios, por lo tanto a la policía le tocaría estar más pendiente. Y creemos que el tema le interesa a todo el mundo porque los chicos en todos los países hay problema de drogadicción sobre todo en los chicos como de nuestra edad.

3. A3-EM-10: bueno con mi grupo tomamos como cosas positivas si se legalizara de manera controlada y responsable que puede disminuir el narcotráfico, ayudaría con los impuestos a los adictos a desintoxicarse. Como aspectos negativos que abría más asesinatos porque la gente se drogaría cada rato, mas 
Revista Tecné, Episteme y Didaxis: TED. Año 2014, Número Extraordinario. ISSN Impreso: 0121-3814, ISSN web: 2323-0126 Memorias, Sexto Congreso Internacional sobre Formación de Profesores de Ciencias. 08 al 10 de octubre de 2014, Bogotá

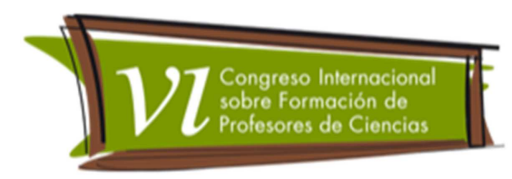

violaciones (...) como reflexión tenemos que este tema es de interés internacional porque toda la gente debe saber de drogas, pues en varios países hay consumo y esto se debe a que los alcaldes, presidentes, jueces y policías han permitido la problemática.

4. A3-EH-4: de nuestro análisis grupal estamos de acuerdo que va a haber más adictos y más delitos por lo que al consumir sustancias psicoactivas no saben lo que hacen y Colombia va a tener críticas de otros países. Si legalizaran la droga habrá menos seguridad por lo que ya podría andar con cualquier clase de droga y no le dirían nada.

Así mismo, los estudiantes participan con posturas enfáticas, existiendo un acercamiento a la autoreflexión y uso parcial de los conocimientos científicos, sociales, afectivos y biológicos del sujeto, que van desde la mutua integración de conceptos, metodologías, procedimientos, datos y organización hasta un esfuerzo alrededor de la problemática común, aproximándose a la etapa social del razonamiento moral, lo cual se evidencia en el episodio 20 donde los estudiantes después del desarrollo de las actividades sobre la cuestión controvertida, toman una postura en contra de la legalización de la dosis personal en Colombia.

1. A7-P: chicos vamos a leer lo que escribieron respondiendo la pregunta ¿Está de acuerdo con la legalización de la dosis personal de sustancias psicoactivas?

2. A7-EM-2: para mí no está bien que legalicen la dosis personal, porque asi la gente va a pensar que la droga está bien y la verdad es que no se dan cuenta que la droga causa mucho daño a nuestro organismo y tampoco saben que nuestro cuerpo todo acumula y poco a poco sufrirán enfermedades muy peligrosas y también se acabaran físicamente nuestro cuerpo, ellos deberían refugiarse en una persona si se sienten tristes, pero no caer en las drogas que es lo más peligroso, deberíamos unirnos para prevenir el consumo, las acciones deberían ser necesarias para evitar el consumo en nuestra comunidad, en el barrio y hasta el planeta entero. Para mí las acciones serian tratar de que nuestro CAl hiciera cada semana una búsqueda de ollas y se llevaran a los menores de edad que estén consumiendo para el bienestar familiar o para un lugar donde les ayuden a dejar las drogas y que también todo el mundo se haga cargo de estudiar más las drogas para que así se den cuenta de que nuevos daños causan y nos informen mucho más de

Temática 1. Enfoque CTS: Alfabetización científica y Cuestiones socio científicas 
Revista Tecné, Episteme y Didaxis: TED. Año 2014, Número Extraordinario. ISSN Impreso: 0121-3814, ISSN web: 2323-0126 Memorias, Sexto Congreso Internacional sobre Formación de Profesores de Ciencias. 08 al 10 de octubre de 2014, Bogotá

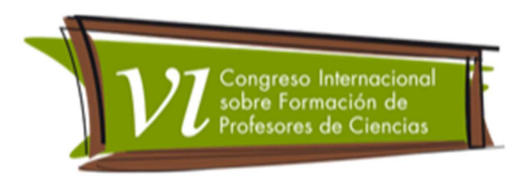

las drogas legales e ilegales porque no solo las ilegales son peligrosas, debemos pensar en vivir sanamente. Dile no a las drogas.

3. A7-EM-5: no estoy de acuerdo porque en alguno países la legalizaron y esos países sucedieron cosas malas como por ejemplo suiza, además creo que la legalización aumentaría el número de drogas y más peligrosas que causan la muerte al consumir mucho desde la cocaína y la marihuana hasta el pegante.

Por lo tanto se puede decir que el razonamiento moral en cada actividad de la cuestión sociocientífica permea las etapas del nivel preconvencional y convencional consideradas por Kohlberg (1992), partiendo del egocentrismo y los intereses individuales hasta la conciencia social que se indica con la postura crítica al considerar diversos factores e implicaciones de la legalización de la dosis personal, así como el despliegue de acuerdos en la resolución de problemas donde la principal preocupación de los educandos es el "bien común", la dignidad y derechos; transcendiendo de esta manera del estudio de teorías, leyes o conceptos científicos para abarcar reflexiones más amplias que destaquen las implicaciones sociales, políticas, económicas y ambientales del progreso tecno científico.

\section{Consideraciones finales}

Los estudiantes involucran implícita y directamente saberes cotidianos, como experiencias de drogadicción de algunos familiares, amigos y vecinos, lo cual implica que el trabajo en el salón de clase es relevante para su realidad, apreciándose en otras investigaciones como es el caso del abordaje de una cuestión sociocientífica en la educación de adultos (Moreno et al., 2011).

Aparte de esos saberes los estudiantes empiezan a utilizar conocimientos académicos tendientes al uso de herramientas generadas a partir de su experiencia escolar para el reconocimiento, comprensión, análisis y reflexión de la cuestión sociocientífica "legalización de la dosis personal" , conllevándolos a una ampliación de su vocabulario usual y al razonamiento moral convencional donde el estudiante manifiesta acuerdos y expectativas a partir de los principios, valores y acuerdos colectivos. Hecho que se evidencia plausiblemente en la participación activa de los educandos, generando críticas y posturas en contra de la despenalización, descriminalización y regulación de las SPA. 
Revista Tecné, Episteme y Didaxis: TED. Año 2014, Número Extraordinario. ISSN Impreso: 0121-3814, ISSN web: 2323-0126 Memorias, Sexto Congreso Internacional sobre Formación de Profesores de Ciencias. 08 al 10 de octubre de 2014, Bogotá

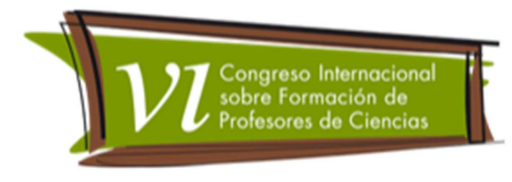

Así es pertinente decir que el abordaje de las CSC contribuye a dicha transformación, porque les permite y les da la oportunidad a los estudiantes de formarse como mejores sujetos, mediante la promoción de valores, habilidades y conocimientos, lo cual conlleva a generar ambientes de negociación en busca de la mejora continua y sobre todo el bien común de los seres del planeta, no solo para los congéneres sino para las sociedades venideras. Es decir ambientes que converjan en acciones, en el hacer desde el conocimiento, la sensatez y con tolerancia moralmente.

\section{Referencias bibliográficas}

Acevedo, J. A., Vázquez, A. y Manassero, M. A. (2003). Papel de la educación CTS en una alfabetización científica y tecnológica para todas las personas. Enseñanza de las Ciencias, 2(2), 80-111.

Aikenhead, G. S. (1987): High-school graduates' beliefs about science-technologysociety. The characteristics and limitations of scientific knowledge.Science Education, 71, 2, 459-487.

Botero, C. A. (2004). La formación de valores en la historia de la educación colombiana. Obtenido el 4 de marzo de 2013, web site: http://www.rieoei.org/deloslectores/932Botero.PDF

Correa, M. (2009). Relación e Impacto del Consumo de Sustancias Psicoactivas Sobre la Salud en Colombia. Tesis de grado. Bogotá, Colombia.

Giroux, H. (1997). Los profesores como intelectuales: hacia una pedagogía crítica del aprendizaje. Paidós/M.E.C. Madrid.

Gobierno Nacional (2011). Estudio nacional de consumo de sustancias psicoactivas en población escolar Colombia - 2011. Obtenida el 5 de abril de 2013, web site: http://odc.dne.gov.co

Kohlberg, L. (1992). Del Desarrollo, la psicología moral. Bilbao (España). Desclée Brauwer del SA.

Hargreaves, A. (2003). Enseñar en la sociedad del conocimiento. Octaedro. Barcelona. 
Revista Tecné, Episteme y Didaxis: TED. Año 2014, Número Extraordinario. ISSN Impreso: 0121-3814, ISSN web: 2323-0126

Memorias, Sexto Congreso Internacional sobre Formación de Profesores de Ciencias. 08 al 10 de octubre de 2014, Bogotá

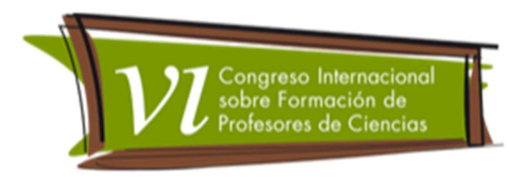

Hodson, D. (2009). Putting Your Money Where Your Mouth Is: Towards an Action-oriented Science Curriculum. Journal for Activist Science \& Technology Education, 1(1).

Jiménez-Aleixandre, M. P. (1998). Diseño curricular: Indagación y razonamiento con el lenguaje de las ciencias. Enseñanza de las Ciencias, 16(2), 203-216.

Martínez, L. F. (2010). A abordagem de questões sociocientíficas na formação continuada de professores de ciências: contribuições e dificuldades. Tesis de Doctorado para la obtención del título de Doctor en Educación en Ciencias, Faculdade de Ciências, Universidade Estadual Paulista, Bauru, Brasil.

Moreno, D. F., Carvalho N., Carvalho, W. L. P. y Martínez L. F. (201 1). A abordagem de uma questâo sociocientifica na educaçâo de adultos. CTS e Educação Científica: Desafios Tendências e Resultados de Pesquis (pp.347- 371). Brasil.

Neira, E. (2008). La interdisciplinariedad de la ciencia de hoy. Obtenida el 2 de enero, 2013, de: http://webdelprofesor.ula.ve/cjuridicas/neirae/pdf/ensayos/14interdisciplinarieda d.pdf

Pinzón, Y. A. y Salazar, L. V. (2012). Enculturación científica a través de la interdisciplinariedad de las cuestiones sociocientíficas. Trabajo de Grado de Maestría, Universidad Pedagógica Nacional.

Rubba, P. A. y Wiesenmayer, R. L. (1988). Coals and competencies for precollege STS education: Recommendation based upon recent literature in environmental education. Journal of Environmental Education, 19, 4, 38-44.

Strike, K.A. y Posner, G. J. (1990). A revisionist theory of conceptual change. Cornell University. Ithaca. New York.

Vergara, A., La huerta, Y., Correa, S. (2003). Posibles implicaciones de la legalización del consumo, producción y comercialización de las drogas en Colombia. Archivos de economía. Obtenida el 20 de abril de 2013, web site: http://www.dnp.gov.co/Portals/0/archivos/documentos/DEE/Archivos_Economia/ 234.pdf. 
Revista Tecné, Episteme y Didaxis: TED. Año 2014, Número Extraordinario. ISSN Impreso: 0121-3814, ISSN web: 2323-0126

Memorias, Sexto Congreso Internacional sobre Formación de Profesores de Ciencias. 08 al 10 de octubre de 2014, Bogotá

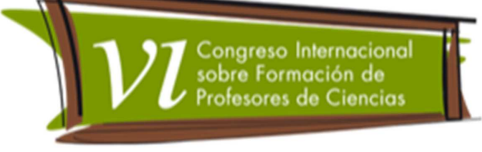

Weissmann, H. (1993), Didácticas especiales. Aique, Buenos Aires.

Zeidler, D. L. y Keefer, M. (2003). The Role of Moral Reasoning and the Status of Socioscientific Issues in Science Education. En D. L. Zeidler (Ed.), The role of moral reasoning on socioscientific issues and discourse in science education. Dordrecht: Kluwer Academic Press. 